\title{
Single-Pulse Sampling Valve Measurements of Wall Layer Hydrocarbons in a Combustion Bomb
}

\author{
A. A. ADAMCZYK, E. W. KAISER, and G. A. LAVOIE \\ Engineering and Research Staff, Ford Motor Company, Dearborn, MI 48121
}

and

\author{
A. J. ISACK \\ University of Michigan, Ann Arbor, MI 48109
}

\begin{abstract}
The processes occurring during head-on flame quench at a cold combustion chamber wall have been studied in a cylindrical combustion bomb. Gas samples were withdrawn from the wall layer using an electrohydraulic sampling valve and were analyzed by gas chromatography. Propane was used as fuel and the experiments were performed at fuel lean $(\Phi=0.9)$ conditions. The results indicate that hydrocarbons present in the quench layer are substantially oxidized within $4 \mathrm{~ms}$ of flame arrival.
\end{abstract}

\section{INTRODUCTION}

The understanding of the intricate processes which ultimately control exhaust hydrocarbon emissions is an extremely important endeavor to the timely development of low-emission engines. Recent sampling valve experiments in engines [1] and numerical calculations [2-4] have cast serious doubts on the long-held view that hydrocarbon material remaining near cold, clean combustion chamber walls after flame quenching controls the eventual engine tailpipe emission level. These engine sampling valve measurements have indicated that only a small amount, less than $10 \%$, of the engine tailpipe emission can be attributed to the quenching process. In addition, recent combustion bomb experiments [5-7], in which extreme care was taken to reduce minute gas storage volumes in the reactors, do not support the existence of a large quench layer contribution to the exhaust. In one reactor experiment,
Adamczyk et al. [6] have shown that the exhaust hydrocarbon emission level is directly related to the crevice volume of the reactor. These experiments are consistent with the suggestion of Westbrook, et al. [4] and the experiments of Blint and Bechtel [8] which indicate that the residual flame quench material rapidly diffuses from the wall layer, can interact with radicals, and is subsequently oxidized.

Because of these results, the processes which are thought to control exhaust hydrocarbon emissions must be carefully reexamined. Since engine conditions are difficult to control, we have performed a detailed single-pulsed sampling valve study to determine the hydrocarbon concentration near a cold clean wall in a static combustion bomb. These combustion experiments were performed using an electrohydraulic sampling valve to extract gas samples dynamically from the wall quench layer. The concentrations of species in the sample were determined by gas chromatography. 
The results of our experiments show that a rapid-acting sampling valve can be used successfully to explore the wall quenching process in a combustion bomb using the sample withdrawn by a single valve event. This is in contrast to multiply averaged pulses analyzed in engine experiments $[1,9]$. In addition, these experiments provide the first transient measurements of the wall quenching phenomenon under nonturbulent laminar conditions. These results, therefore, complement the engine experiments in which turbulence and fluid motion may strongly influence the results. The results support the view that flame quench hydrocarbons rapidly oxidize and do not contribute significantly to engine tailpipe hydrocarbon emissions. However, they do not resolve the issue as to whether the residual background hydrocarbon level in combustion bombs arises from micro crevice volumes in the reactor, a minute quench layer contribution, or another source.

\section{EXPERIMENTAL}

These experiments were performed in a low-crevice-volume combustion bomb. It was fabricated from a Matheson $500 \mathrm{~cm}^{3}$, monel sample container, with a surface-to-volume ratio $S / V$ equal to $1.1 \mathrm{~cm}^{-1}$. A diagram of the experimental apparatus is shown in Fig. 1. The reactor contains four access ports. Mounted in these four ports are a conventional $18 \mathrm{~mm}$ spark plug, an electrohydraulic sampling valve, an inlet-exhaust valve and a Kistler piezoelectric pressure transducer. Since crevice volumes in the reactor can seriously influence measurements, the volume between the central spark electrode and the plug ground was filled with epoxy, and all access port threads were coated with epoxy.

Gas samples were extracted using the electrohydraulic sampling valve described in LoRusso et al. [1]. The valve was located approximately in the end gas region of the combustion bomb and was flush mounted to the reactor wall (see Fig. 1). However, since it is likely that the flame front is convex as it propagates down the length of the reactor, the flame will reach the sample valve location at the end of the tube before the last of the fuel is consumed in the corners. Thus, the possibility exists that the flame will reach the sample volume prior to peak pressure.

Typical open-close times of the valve ranged from 0.3 to $1.0 \mathrm{~ms}$. A cross-sectional diagram of the valve tip region is shown in Fig. 2a. The valve stem was ground flush with the valve body and in all experiments the valve lift was always much smaller than the characteristic sample dimension $d_{\mathrm{s}}$. The valve seat was circular with a $6.25 \mathrm{~mm}$ diameter. Flow into this circular orifice forms a toroidal-shaped flow profile above the valve surface. The cross-sectional shape of this annulus and the distance $d_{\mathrm{s}}$ can be approximately determined by means of the quasi-steady, constant density, viscous sink flow analysis presented by Landau and Lifshitz [10] and LoRusso et al. [9] .

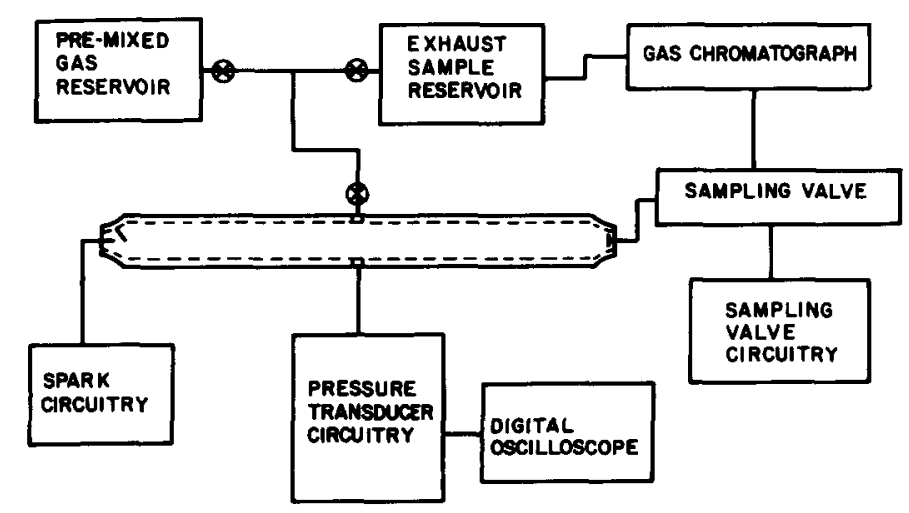

Fig. 1. Schematic diagram of combustion bomb apparatus. Volume of bomb is 500 $\mathrm{cm}^{3}$, with a surface-to-volume ratio of $1.1 \mathrm{~cm}^{-1}$. 

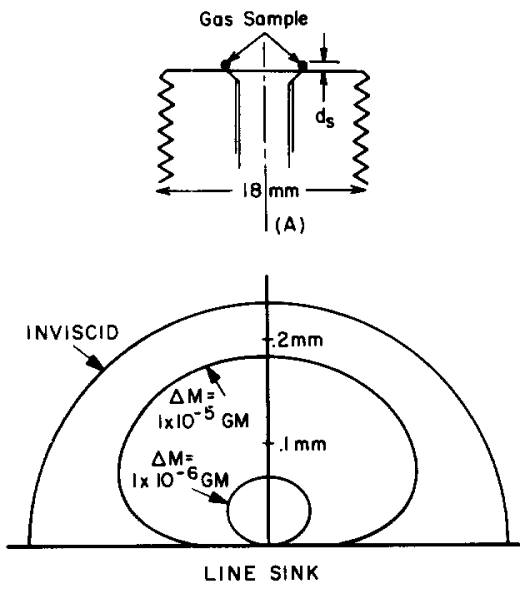

(B)

Fig. 2. Schematic diagram of valve tip geometry $(A)$ and calculated sample flow cross section $(B)$. Flow cross sections were generated using the peak pressure in the reactor, $980 \mathrm{kPa}$, and using the wall temperature $300^{\circ} \mathrm{K}$.

Typical calculated flow profiles for the mass flow range used in these experiments are shown in Fig. 2b. The gas density used for this calculation was equal to the density evaluated at the wall temperature $\left(300^{\circ} \mathrm{K}\right)$ and at the peak pressure in the reactor $(980 \mathrm{kPa})$. For low mass flow rates into the valve, the cross-sectional shape of the flow profile is approximately circular. As the mass inducted into the valve increases, the maximum sampling distance from the wall increases, and the cross-sectional shape near the wall becomes flattened. At large flow rates, the cross-sectional shape approaches that of flow into an inviscid line sink having a semicircular cross section.

For several reasons, the predictions of the flow model can deviate from the actual flow conditions existing during the time of sampling. We recognize that temperature gradients near the wall and the transient nature of the flow are not included in the analysis. For our purposes, the assumptions of constant temperature at $T=T_{\text {wall }}$ and laminar flow are reasonable since the majority of hydrocarbons in a quench layer would be located in a region close to the wall within the viscous sublayer and would have a temperature $T \leqslant 800^{\circ} \mathrm{K}$. The precise shape of the flow pattern far away from the wall is not critical to our purpose since the quench distance is small compared to the sampled distance. Also, flow profiles derived from a more accurate flow analysis including temperature gradients and transient effects would be expected to join smoothly with the profiles calculated using the quiescent constant temperature analysis in the region near the wall.

Regarding possible oxidation inside the valve, heat transfer calculations for the flow in the inlet seat region $(0.25 \mathrm{~mm})$ and a typical valve lift of $0.008 \mathrm{~mm}$ have shown that the gas temperature would be rapidly reduced once the gases have entered the valve. An arbitrary initial gas temperature of $1500^{\circ} \mathrm{K}$ would be reduced to $700^{\circ} \mathrm{K}$ within $1 \mu \mathrm{s}$ for the valve geometry stated above. This time scale is much less than the characteristic time scales for oxidation at $1500^{\circ} \mathrm{K}$ of $0.020 \mathrm{~ms}$ from Lavoie [11], ruling out the possibility of significant oxidation occurring inside the valve.

Leakage through the valve was determined by pressurizing the combustion bomb to $600 \mathrm{kPa}$ and measuring the rate of pressure rise in an evacuated $12 \mathrm{~cm}^{3}$ sampling volume attached to the valve. At the initial pressure in the bomb, the average static leak rate was $1.7 \times 10^{-10} \mathrm{~g} / \mathrm{s}$. With an average exposure time to unburned mixture prior to firing of $30 \mathrm{~s}$, the average leakage in to the sample manifold was $5 \times 10^{-9} \mathrm{~g}$ per sampling event. This corresponds to approximately $0.0007-0.7 \%$ of the sample mass inducted into the valve, depending on the sample size extracted.

In a typical experiment, the combustion bomb was filled with premixed propane-air and allowed to sit for approximately $30 \mathrm{~s}$. The mixture was then ignited by a capacitive discharge spark source and a gas sample was dynamically collected by the sampling valve at the opposite end of the reactor. This sample was removed from the bomb wall region into an evacuated $12 \mathrm{~cm}^{3}$ sample manifold at a designated time after ignition. The amount of material extracted from the wall region as determined by the pressure rise in the sample manifold ranged from $7 \times 10^{-7}$ to $7 \times 10^{-4} \mathrm{~g}$ in a single valve pulse. In addition, exhaust samples were withdrawn from the bulk gas through the inlet-exhaust valve into a $2000 \mathrm{~cm}^{3}$, evacuated Pyrex container at either 5 or $10 \mathrm{~min}$ after ignition. The gas samples were injected into a gas chromatograph and analyzed for stable $\mathrm{C}_{1}-\mathrm{C}_{4}$ hydrocarbons, $\mathrm{O}_{2}, \mathrm{~N}_{2}, \mathrm{CO}$, and $\mathrm{CO}_{2}$. 
For all data presented, propane and air were used as fuel and oxidizer at a fuel-air equivalence ratio of 0.9 . The initial pressure in the bomb prior to ignition was $200 \mathrm{kPa}$, and the wall temperature was $300^{\circ} \mathrm{K}$.

\section{RESULTS AND DISCUSSION}

For the stated initial conditions, flame propagation through the reactor takes approximately $170 \pm 6 \mathrm{~ms}$. During this time, the pressure rises from its initial value of 200 to $980 \mathrm{kPa}$. This is considerably lower than the adiabatic peak pressure of $1785 \mathrm{kPa}$ for a constant volume process such as is observed for a centrally ignited combustion bomb. The reduced maximum pressure is caused by the substantial heat transfer from the burned gas region in the long thin reactor. Continued heat loss causes the pressure in the reactor to drop from 980 to $300 \mathrm{kPa}$, within $300 \mathrm{~ms}$ of peak pressure.

The exhaust hydrocarbon concentration from the bomb after $5 \mathrm{~min}$ is $27 \mathrm{ppmC}_{1}$, and greater than $95 \%$ of this hydrocarbon material is propane (fuel). This result is slightly higher than the previous observations ( $15 \mathrm{ppmC}_{1}$ ) of Adamczyk et al. [6] performed in a similar reactor because additional thread crevices are present.

Hydrocarbon concentrations were obtained dynamically as a function of time relative to the time of peak pressure for each experiment at a constant mass $\left(6 \times 10^{-5} \mathrm{~g}\right)$ inducted into the valve (time scan) and as a function of mass inducted into the valve at a constant time after peak pressure (mass scan). The mass scan data were obtained at 15,80 , 170 , and $400 \mathrm{~ms}$ after peak pressure.

Figure 3 presents the measured propane (fuel), ethylene, methane, carbon dioxide, and carbon monoxide concentrations in ppm as a function of time relative to the time of peak pressure for each individual experiment. Each set of hydrocarbon concentration data represents one independent bomb firing. Prior to the time corresponding to flame arrival, which we define as the time when the propane concentration begins to drop from its initial concentration, the concentrations of these species were equal to their preignition values for a $\Phi=0.9$ propane-air mixture. The initial propane

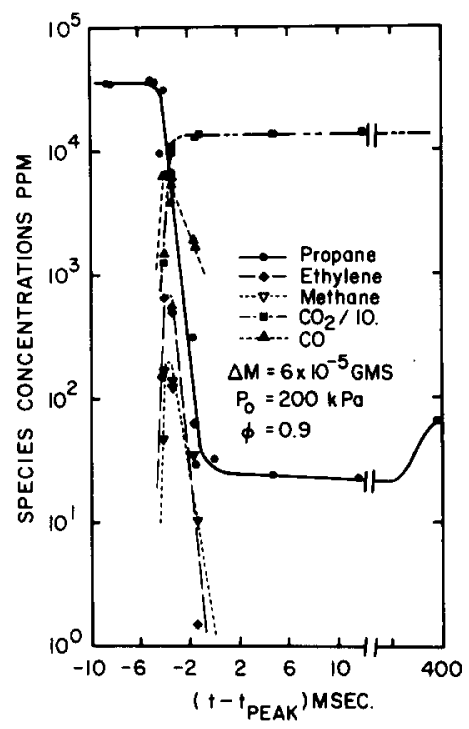

Fig. 3. Sampled species concentration as a function of time relative to peak pressure in the reactor. Amount of mass inducted into the valve equals $6 \times 10^{-5} \mathrm{~g}$. At $t_{\text {peak }}(\cong 170 \mathrm{~ms}$ ), the pressure in the reactor was $980 \mathrm{kPa}$. Wall temperature equaled $300^{\circ} \mathrm{K}$.

concentration was $36,000 \mathrm{ppm}$, with minor fuel contaminant species $<10 \mathrm{ppm}$. At the time of flame arrival, the propane concentration drops from the initial value of $36,000 \mathrm{ppm}$ to approximately 25 ppm within $4 \mathrm{~ms}$. During this interval, the intermediate hydrocarbon species and $\mathrm{CO}$ concentrations reach a peak at a time when the propane concentration drops to approximately $9000 \mathrm{ppm}$. The peak concentration of ethylene and methane are 700 and $180 \mathrm{ppm}$, respectively. The peak acetylene $(230 \mathrm{ppm})$ and propylene $(270 \mathrm{ppm})$ concentrations are not shown in Fig. 3 , but also occur at the same time. These intermediate hydrocarbon species concentrations then fall below the detection limit (10 ppm for $\mathrm{CH}_{4}$ and $1 \mathrm{ppm}$ for the other hydrocarbons) within $3 \mathrm{~ms}$ of flame arrival at the sample volume. These measurements are in qualitative agreement with the measurements of wall layer hydrocarbon concentrations obtained by LoRusso et al. [1] in a CFR engine and are consistent with the simple four-step HC oxidation mechanism presented in Hautmann et al. [12]. The observation of the sharp rise in propane oxidation products simultaneous with the sharp drop in propane concentration is con- 
sistent with, but does not prove, the theory that the flame quenches short of the combustion shamber wall. Residual propane present in a wall quench layer after flame quenching can diffuse into hot bulk gas with the formation of intermediate products which are subsequently consumed within $4 \mathrm{~ms}$ after flame arrival. Such rapid diffusion into the hot bulk gas is expected on the basis of reasonable estimates of diffusion coefficients for the light hydrocarbon species $\left(D=0.01 \mathrm{~cm}^{2} / \mathrm{s}, \mathrm{P}=9.5 \mathrm{~atm}\right.$, and $\left.T=300^{\circ} \mathrm{K}\right)$. Combined with an estimated thickness of the wall quench layer at the time of flame arrival $(\sim 0.050 \mathrm{~mm})$ as calculated from the correlations of Lavoie [11] for one-wall quench distance, this gives a mean diffusion time $X^{2} / 2 D$ of approximately $1.25 \mathrm{~ms}$, which is consistent with the observed falloff time.

From the inducted mass of $6 \times 10^{-5} \mathrm{~g}$ used to generate Fig. 3, the maximum distance from the wall from which gases are sampled is $\sim 0.4 \mathrm{~mm}$. Since this is greater than the typical flame thickness at these pressures, it is possible that the initial falloff of propane in Fig. 3 is affected by flame propagation through the sample volume. This process could take $2-3 \mathrm{~ms}$. However, at approximately a distance from the wall equivalent to one flame thickness, flame propagation should cease, as predicted by many investigators [2-4] . From the correlations of Lavoie [11] this quench distance, at a pressure of $980 \mathrm{kPa}$, is of the order of $0.050 \mathrm{~mm}$. If the flame stops at this position with no further oxidation of gases occurring in the layer, the $\mathrm{HC}$ concentration in the sampled gases would be greater than $500 \mathrm{ppm}$ propane. However, the $\mathrm{HC}$ concentration decreases to a minimum value of approximately $25 \mathrm{ppm}$ propane at this flow rate. Even though the detailed structure of the HC falloff cannot be determined with absolute certainty due to a lack of knowledge of the flame position within the sampling region, it is certain that no significant amount of quench layer material remains $4 \mathrm{~ms}$ after flame arrival.

After reaching a minimum of $25 \mathrm{ppm}$, the concentration of propane slowly rises over a period of $400 \mathrm{~ms}$ to $85 \mathrm{ppm}$. The other hydrocarbon species remain low $(<2 \mathrm{ppm})$ and are found to be less than $0.5 \mathrm{ppm}$ in the well-mixed sample. Although we have not measured the wall hydrocarbon concentration at long times after peak pressure for this value of mass inducted into the valve, we have measured the hydrocarbon concentrations at a higher inducted mass of $\Delta M=4 \times 10^{-4} \mathrm{~g}$ from the time corresponding to peak pressure to $5 \mathrm{~min}$ after peak pressure. At this inducted mass, the trends in hydrocarbon concentration are similar to those presented in Fig. 3 with the fuel concentration dropping within $4 \mathrm{~ms}$ of flame arrival, rising during the time when the pressure in the reactor is falling due to heat transfer through the reactor walls, and falling to the well-mixed exhaust concentration at 5 mins after peak pressure. We believe this slow rise and fall to be the result of hydrocarbons from sources other than wall quench, in particular, from crevices near the sampling valve which are released by depressurization of the bomb due to heat transfer and are transported by diffusion and residual gas motion in to the range of the sampling valve. These general features of the data at long times also resemble those observed in the engine experiments of LoRusso et al. [1,9].

Figure 4 presents the data obtained by varying the sampled mass into the valve at four times after flame arrival $(15,80,170$, and $400 \mathrm{~ms}$.). As described previously, increasing the sampled mass increases the distance from the wall $d_{\mathrm{s}}$ from which material is withdrawn. At 15,80 and $170 \mathrm{~ms}$ after flame arrival, the propane concentration falls rapidly with increasing sample mass. As will be discussed later, this is indicative of propane either

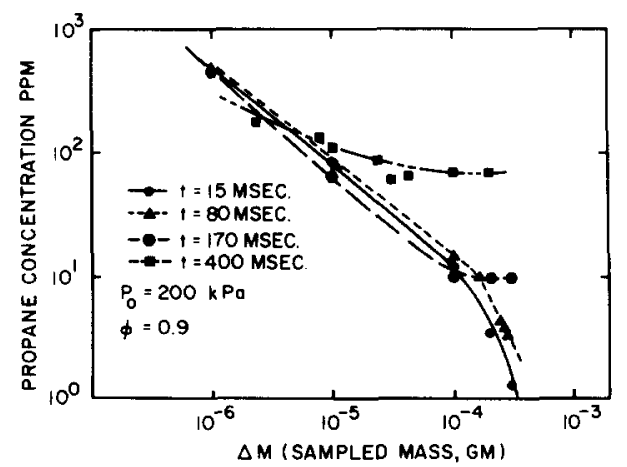

Fig. 4. Propane concentration as a function of sampled mass at $15,80,170$, and $400 \mathrm{~ms}$ after peak pressure. 


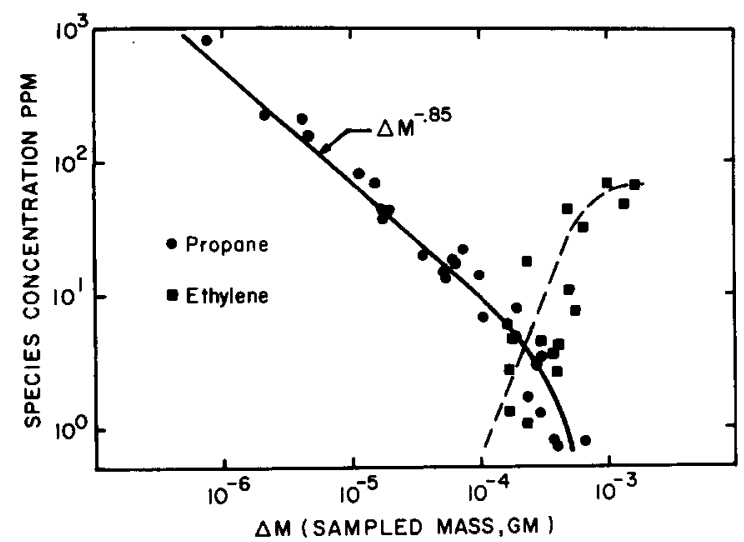

Fig. 5. The propane (fuel) and ethylene (intermediate species) concentration as a function of sampled mass. The sample time, corresponding to a minimum propane concentration, ranged from 8 to $20 \mathrm{~ms}$ after peak pressure.

located in a thin wall layer or arising from valve defects. However, the propane concentration versus sampled mass profile at $400 \mathrm{~ms}$ falls much more slowly, decreasing only a factor of 2 with a variation of a factor of 65 in sampled mass. This type of profile can only be observed if the propane is present at approximately uniform concentration to distances from the wall greater than or equal to the maximum sampled distance. At $\Delta M \sim 2 \times 10^{-4} \mathrm{~g}$, with $P=200 \mathrm{kPa}$ and $T=$ $300^{\circ} \mathrm{K}, d_{\mathrm{s}}=2 \mathrm{~mm}$, indicating that the propane observed at $400 \mathrm{~ms}$ is present to distances at least $2 \mathrm{~mm}$ from the wall. This result is consistent with the above hypothesis that the observed later rise in propane concentration to levels above the exhaust concentration can be a result of material diffusing into the sampling region from a source such as a crevice.

Fig. 5 presents both the propane (fuel) concentration and the principal product (ethylene) concentration as a function of inducted mass into the valve at times between 8 and $20 \mathrm{~ms}$ after flame arrival. These times were chosen since the hydrocarbon concentration has reached its minimum value and remains constant over this range of times. For sampled mass less than $\Delta M=$ $10^{-4} \mathrm{~g}$, the propane concentration falls monotonically with increasing $\Delta M$, and is proportional to $\Delta M^{-\mathbf{0 . 8 5}}$ within experimental error. In this region, the ethylene concentration is below the detection limit $\left(1.5 \mathrm{ppm}\right.$ at $\left.\Delta M=5 \times 10^{-5} \mathrm{~g}\right)$.
A sharp break occurs at $\Delta M=2 \times 10^{-4} \mathrm{~g}$ in both the ethylene and the propane concentrationsmass profiles. The propane, which is at relatively low concentrations, decreases much more rapidly than $\Delta M^{-\mathbf{0 . 8 5}}$. The ethylene concentration rises sharply and then begins to level off for $\Delta M \sim$ $10^{-3} \mathrm{~g}$. The sharp decrease in propane concentration may result from pyrolysis caused by mixing of unburned residual propane from a wall layer or valve seat crevices with hot gases during the sampling procedure. Increasing the sampled mass will increase the average temperature of the sample. Because of the high activation energy of propane pyrolysis, we expect a sudden onset of pyrolysis at a particular sampled mass and a rapid decrease in propane concentration for larger inducted mass, and this is observed. Ethylene is known to be the major intermediate product formed during propane oxidation (Hautmann, et al. [12]), and a rise in ethylene concentration would be expected to result from the propane decomposition. However, the ethylene rises to approximately $65 \mathrm{ppm}$, approximately 10 times greater than would be expected by conversion of the observed $6 \mathrm{ppm}$ decrease in propane from the $\Delta M^{-\mathbf{0 . 8 5}}$ curve into ethylene. The likely explanation for this observation is that much of the increased ethylene results from inclusion in the sampled volume of partially oxidized propane from the same crevices which produce the hydrocarbon rise at long times after flame arrival. The rise in ethylene concentration occurs for $\Delta M$ between $2 \times 10^{-4}$ and $1.5 \times 10^{-3} \mathrm{~g}$. For these sampled masses, $d_{\mathrm{s}}=2$ and $5.5 \mathrm{~mm}$, respectively. Thus, in this sampled mass region, the sampled volume begins to overlap the thread crevices in the valve which are located $5 \mathrm{~mm}$ from the valve seat, providing an explanation for the sharp increase in total hydrocarbon concentration at masses larger than $\Delta M=2 \times 10^{-4} \mathrm{~g}$. Because of the likelihood that inclusion of material from crevices and possible burnup during the sampling process occurs for $\Delta M>2 \times 10^{-4} \mathrm{~g}$, the remaining discussion will be focused on the data obtained for $\Delta M<1 \times 10^{-4} \mathrm{~g}$, which are unaffected by such phenomena.

By using the data in Fig. 5, a calculation to determine an upper-limit contribution of residual 


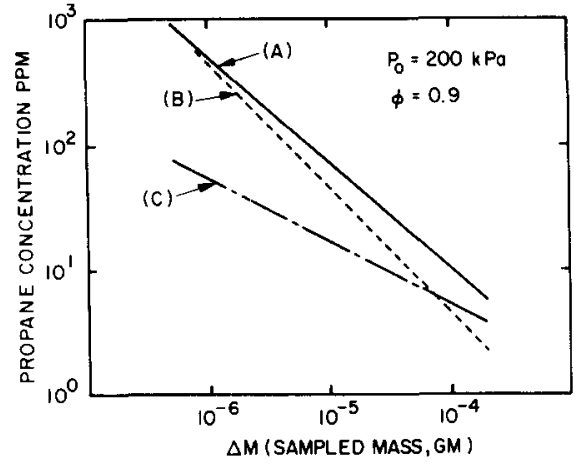

Fig. 6. Propane concentration as a function of sampled mass. Curve $A$ is a best-fit curve to the raw sampling valve data from Fig. 5. Curve $B$ is an estimate of valve tip crevice or valve leakage contribution as determined by the separation analysis. Curve $C$ is an estimate of the residual quench layer contribution as determined by the separation analy sis.

quench layer hydrocarbons to the well-mixed exhaust has been made. The calculation was performed at an inducted mass equal to $1.0 \times 10^{-5} \mathrm{~g}$. The corresponding sampled propane concentration was equal to $75 \mathrm{ppm}$. The assumptions used in this upper-limit calculation were these: (1) the flow profile is accurately represented by the flow model for viscous sink flow described in [10]; (2) the sampled hydrocarbons are from wall quench only and are not contaminated by valve leakage or by crevices in the valve tip (these effects will be treated later); (3) the propane concentration in the wall layer has a Gaussian profile in distance from the wall and the wall propane concentration is equal to that of the unburned mixture (this produces the thinnest possible layer and consequently the poorest entrainment of quench layer material into the sampled volume); and (4) all sampled gas is entrained into the valve with no further burnup. For these conditions, the equations to determine the layer thickness, surface concentration, and bulk gas contribution are presented in detail in LoRusso et al. [9]. The calculation shows that the propane entrained into the sampling valve would arise from a quench layer which is approximately $2.8 \mu \mathrm{m}$ thick and would contain $7.3 \times 10^{-8} \mathrm{~g} / \mathrm{cm}^{2}$ of propane. If this layer were evenly distributed along the reactor surface, it would yield a well-mixed exhaust propane concentration of approximately
$22 \mathrm{ppm}$, a factor of 2 higher than the observed bulk sample concentration of $9 \mathrm{ppm}$.

If accurate estimates of valve leakage or valve tip crevice effects could be made, the resulting quench layer contribution to the exhaust would be lower than this upper limit, since extremely small amounts of valve leakage or valve tip crevices may significantly increase the sampled propane concentration at these low HC levels (see Ref. [9]). To estimate the contribution valve imperfections may have on the sampled propane concentration, the measured curve of Fig. 5 (shown as curve $A$ in Fig. 6) was separated into two curvescurves $B$ and $C$ in Fig. 6, corresponding to crevice and quench layer portions, respectively. This separation of data is possible because of the different expected behavior with mass inducted of crevice versus quench layer contributions. Propane arising from sampling valve leakage or a crevice in the valve seat would be proportional to $\Delta M^{-1.0}$ because the constant contribution of unburned propane from the crevice or leakage would be simply diluted by the burned gas, which contains a negligible concentration of propane. For the sampling conditions employed here, the mass dependence expected for quench layer material would be approximately $\Delta M^{-\mathbf{0 . 5}}$, as determined using the analysis of Landau and Lifshitz [10] and LoRusso et al. [9] (see Fig. 2b).

Thus, if it is assumed that the observed propane concentration dependence of $\Delta M^{-0.85}$ is caused partially by the dilution of valve seat crevice material or leakage of unburned gases into the valve and partially by the induction of a small amount of residual quench layer material into the valve, curve $A$ may be separated into two curves approximately representing each of these contributions. Curve $B$ in Fig. 6 represents the amount of hydrocarbon material which is due to valve tip crevices or leakage of unburned gas into the valve prior to flame arrival at the valve and is proportional to $\Delta M^{-1}$, while curve $C$ represents the residual quench layer contribution inducted into the valve with a concentration proportional to $\Delta M^{-0.5}$.

The numerical separation of curve $A$ into the components contributed by quench layers and 
crevices is accomplished by evaluating the constants $B_{1}$ and $B_{2}$ in Eqs. (1) and (2), respectively:

$(P)_{\mathrm{q} 1}=B_{1} \Delta M^{-0.5} \quad($ curve $C)$,

$(P)_{\mathrm{cv}}=B_{2} \Delta M^{-1.0} \quad($ curve $B)$,

where $(P)_{\mathbf{Q} 1}$ is the propane concentration due to the quench layer and $(P)_{\mathrm{cv}}$ is the propane concentration due to valve tip crevice volume or leakage into the valve. An additional stipulation to the separation procedure is that the sum of the propane concentrations of each contribution must fall on curve $A$ at two chosen end points:

$(P)_{\text {curve } A}=(P)_{\mathrm{ql}}+(P)_{\mathrm{cv}}$.

We calculated the constants $B_{1}$ and $B_{2}$ using the propane concentrations from curve $A$ at masses equal to $1 \times 10^{-6}$ and $1 \times 10^{-4} \mathrm{~g}$, which are $500 \mathrm{ppm}$ and $10 \mathrm{ppm}$, respectively. This is the maximum range of straight line behavior and should yield the most accurate separation. From Eqs. (1)-(3), $B_{1}$ equals $5.5 \times 10^{-2} \mathrm{ppm} \mathrm{g} \mathrm{g}^{0.5}$ and $B_{\dot{z}}=4.4 \times 10^{-4} \mathrm{ppm} \mathrm{g}$. From curve $C$, the contribution of the hydrocarbon concentration from a residual quench layer to the wellmixed exhaust may now be estimated more accurately than in the upper-limit calculation carried out previously. On this curve, the propane sample concentration at a mass equal to $1 \times 10^{-5} \mathrm{~g}$ is $17 \mathrm{ppm}$. With this estimate of residual hydrocarbon material from a quench layer, the corresponding quench layer thickness, surface concentration, and contribution to the exhaust were calculated using the flow model and the same assumptions as before, and were calculated to be 0.7 $\mu \mathrm{m}, 1.7 \times 10^{-8} \mathrm{~g} / \mathrm{cm}^{2}$, and $5 \mathrm{ppm}$ propane, respectively. This exhaust concentration is approximately equal to the exhaust propane concentration observed in a low-crevice version of this reactor by Adamczyk et al. [6]. In addition, using the estimated leak rate of $5 \times 10^{-9} \mathrm{~g}$ per sampling event presented earlier, an average valve leakage contribution to the sample can be estimated from the following expression:

$$
\begin{aligned}
& {[\mathrm{HC}]_{\text {leakage }}} \\
& \doteq \frac{[\mathrm{HC}]_{\mathrm{o}} \cdot \Delta M_{\text {leakage }}}{\Delta M_{\text {leakage }}+\Delta M_{\text {sample }}},
\end{aligned}
$$

where $[\mathrm{HC}]_{0}$ is the concentration of hydrocarbons in the reactor prior to combustion. At an inducted mass into the valve of $1 \times 10^{-5} \mathrm{~g}$, the leakage contribution is estimated to be $\sim 18$ ppm propane. This estimated leakage contribution is approximately equal to the leakage contribution as determined by the separation analysis (see Fig. 6, curve $C$ ).

In summary, these sampling valve measurements of wall layer hydrocarbon concentration have produced estimates of residual quench layer thickness, hydrocarbon surface concentration, and the quench layer contribution to the exhaust emission from this reactor. We have used both raw data and the results of a separation analysis to eliminate effects of valve imperfections, such as leakage and valve crevices. Using the raw data, which provide an upper-limit calculation, the residual quench layer thickness, quench layer surface concentration, and quench layer contribution to the exhaust emission were determined to be $2.8 \mu \mathrm{m}, 7.3 \times 10^{-8} \mathrm{~g} / \mathrm{cm}^{2}$, and $22 \mathrm{ppm}$ propane, respectively. Additionally, if the separation analysis to estimate valve imperfections is used, approximately accounting for leakage or valve crevices, the quench layer thickness, quench layer surface concentration, and the quench layer contribution to the exhaust emission are $0.7 \mu \mathrm{m}, 1.7 \times 10^{-8} \mathrm{~g} / \mathrm{cm}^{2}$, and $5 \mathrm{ppm}$ propane, respectively.

These results are in good agreement with the estimated upper limits for quench layer hydrocarbon surface concentration of $2.4 \times 10^{-8}$ $\mathrm{g} / \mathrm{cm}^{2}$ made by Lo Russo et al. [1] in a CFR engine under turbulent flow conditions, and with estimates of residual quench-layer hydrocarbon surface concentration obtained in a combustion bomb by Sellnau et al. [7] . 


\section{CONCLUSIONS}

The results show that the hydrocarbons in the wall layer are rapidly oxidized after flame arrival within a time less than $4 \mathrm{~ms}$. This closely agrees with the conclusions of LoRusso et al. [1] obtained from experiments in a CFR engine at $40^{\circ}$ after TDC. They also agree with the predictions of Westbrook et al. [4] and the experiments of Blint and Bechtel [8], who showed that the wall layer molecules can rapidly diffuse from the wall layer, can interact with radicals, and are oxidized over this time scale.

The measurements suggest that the propane concentration measured by the sampling valve $15 \mathrm{~ms}$ after peak pressure may be controlled by a combination of residual quench layer hydro. carbons and valve tip crevice volume or valve leakage hydrocarbons. They also suggest that material from crevices near the valve can be transported into the sample volume for a time after peak pressure which is greater than $200 \mathrm{~ms}$ or for large sample mass at shorter times.

The results obtained from upper-limit calculations of the sampling processes and a simple separation analysis used to estimate valve imperfection effects during sampling indicate that residual quench layer material may contribute from 5 to $22 \mathrm{ppm}$ propane to the well-mixed exhaust sam. ple. This suggests that a significant fraction of the extremely low exhaust background hydrocarbon level in clean combustion bombs may arise from a residual of the quenching process.

The authors wish to thank J. A. LoRusso for performing the numerical flow calculations for the sampling valve, maintaining the sampling valve, and providing guidance in its use.

\section{REFERENCES}

1. LoRusso, J. A., Lavoie, G. A., and Kaiser, E. W., Combustion Science and Technology 25:121 (1981).

2. Kurkov, A. P., and Mirsky, W., Twelfth Symposium (International) on Combustion, The Combustion Institu te, 1968 , p. 615 .

3. Adamczyk, A. A., and Lavoie, G. A., SAE Transactions 87, SAE Paper No. 780969, Society of Automotive Engineers, 1978.

4. Westbrook, C. K., Adamczyk, A. A., and Lavoie, G. A., Combust. Flame 40:81 (1981).

5. Bergner, P., Eberius, H., and Pokorny, H., Third Alcohols Symposium, May 1979, Asilomar, California.

6. Adamczyk, A. A., Kaiser, E. W., Cavolowsky, J. A., and Lavoie, G. A., 18th Symposium (International) on Combustion, The Combustion Institute, 1980, p. 1695.

7. Sellnau, M. C., Springer, G. S., and Keck, J. C., SAE Paper No. 810148, Society of Au tomotive Engineers, 1981.

8. Blint, R. J., and Bechtel, J. H., SAE Paper No. 820063, Society of Automotive Engineers, 1982.

9. LoRusso, J. A., et al., Combustion Science and Tech . nology (1983), in press.

10. Landau, L. D., and Lifshitz, E. J., Fluid Mechanics, Pergamon Press, 1959, pp. 81-86.

11. Lavoie, G. A., SAE Paper No. 780229, Society of Automotive Engineers, 1978.

12. Hautman, D. J., Dryer, F. L., Schug, K. P., and Glassman, I., Combustion Science and Technology 25:219 (1981).

Received 5 August 1982; revised 11 February 1983 